\title{
Study on Push/ Pull Strategy Decision Taken by Organizations for Their Products and Services
}

\author{
Singh Sarbjit \\ Institute of Management Technology, Nagpur, India
}

Copyright $\bigcirc 2017$ by authors, all rights reserved. Authors agree that this article remains permanently open access under the terms of the Creative Commons Attribution License 4.0 International License

\begin{abstract}
This paper attempts to find out whether organizations should follow a push strategy or pull strategy and how their supply chain works. Depending upon the organization, it can be a mix of both the strategies. This study works on factors which provides best decision fit for organizations and their business. It also discusses the advantages and disadvantages both the strategies and how the life cycle of the product helps in determining which strategy to be used. The case of dealing with perishable goods has been considered. This study also proposes about the inventory levels for each strategy.
\end{abstract}

Keywords Push Strategy, Pull Strategy, Inventory Management, Perishable Goods, Uncertain Demand, Kanban

\section{Introduction}

The Supply chain is a vital part of all the businesses and in today's competitive environment, designing and managing the supply chain properly is equivalent to managing the complete business. The strategy chosen by the organization determine the complete business model followed by the organization. Supply chains are deigned on basis of manufacturing of a product, delivered to wholesalers, retailers and made available to the customers. The most common strategies for moving from upstream to downstream sites are push and pull strategies, or some mix of both. The basically organization's all processes in supply chain management fall into any one of the two categories depending on the timing of their execution with respect to the customer demand. These processes are either Pull/Push System as defined below.

Definition of Push and Pull System as per Business Dictionary

${ }^{1}$ Push system is a manufacturing system in which production is based on a projected production plan and where information flows from management to the market, the same direction in which the materials flow.

${ }^{2}$ Pull System is a manufacturing system in which production is based on actual daily demand (sales), and where information flows from market to management in a direction opposite to that in traditional (push) systems.

${ }^{1} \mathrm{http}: / / \mathrm{www} \cdot$ businessdictionary.com/definition/push-sys tem.html

${ }^{2} \mathrm{http} / / / \mathrm{www} \cdot$ businessdictionary.com/definition/pull-syst em.html

Sarkar, B.R and Futzsimmons J.A [1] worked on the performance of push and pull system: a simulation and comparative study. Pyke D.F and Cohen M.A [2] worked on implementation of push and pull in manufacturing and distribution. Zhao, $X$ and Lee T.S [4] worked on freezing the master production schedule for material requirement planning system under demand uncertainty. Harison [5] has suggested deciding about the pull or pushing strategy depending on the certainty demand of the product. Kim, Chhajed and Palekar [6] have done a comparative study of the performance of the push and pull systems in the presence of emergency orders. Mashuchun, Davis and Patterson [7] studied the performance difference of push and pull control strategies for supply network management in a make-to-stock-environment. In this study the factors, which would help to determine push or pull strategy has been studied and also why combination of both is required in most cases has been discussed.

\section{Push Based Supply Chain Strategy}

In this strategy the material is pushed to the supply chain from the initial raw material end to the customer end on the basis of the demand forecasts. At the end of the supply chain, the finished goods await customers' orders. Naturally inventory in various forms (raw material, work-in-progress and finished goods) exists at the various points in the supply chain, 'just-in-case' it may be required. Push process operate in an uncertain environment in which customer demand is not yet known. 


\section{Pull Based Supply Chain Strategy}

In this strategy a customer order pulls material into the supply chain. However, the catch here is that the customer should be willing to wait during the time the product is being processed in the supply chain. If the waiting time on part of the end customer is stretched too long, this strategy starts failing. Pull Process operate in an environment in which customer demand is known. A major advantage of this strategy is that in an ideal scenario, there would be zero inventories all across the supply chain.

Initially most of the organizations were following Push system but in the last two decades pull system is pushing the push system. These systems have led to the development of lean manufacturing and Kanban ${ }^{3}$ System. Although all sectors cannot go for the pull system and some have to follow push. This study tries to find out which system is best fit for which type of organization.

${ }^{3} \mathrm{Kanban}$ is a Japanese word meaning flag or signal, and is a visual aid to convey the message that action is required

\section{Some Known Examples of Pull/Push Strategy}

Hopp and Spearman [7] consider some of the most common systems found in industry and the literature and classify them as either push or pull.

- $\quad$ MRP is a push system because releases are made according to a master production schedule without regard to system status. Hence, no a priori WIP limit exists.

- Classic Kanban is a pull system. The number of kanban cards establishes a fixed limit on WIP.

- Classic Base Stock System is, somewhat surprisingly, a push system because there is no limit on the amount of work in process in the system. This is because backorders can increase beyond the basestock level.

- Installation stock $(\mathrm{Q}, \mathrm{r})$ is also a push system as are echelon stock $(\mathrm{Q}, \mathrm{r})$ systems because neither imposes a limit on the number of orders in the system.

- CONWIP is a pull system because it limits WIP via cards similar to kanban. An important difference from kanban from an implementation standpoint is that the cards are line specific rather than part number specific. However, from a push/pull perspective, CONWIP cards limit WIP in the same manner as kanban cards.

- $\quad(\mathrm{K}, \mathrm{S})$ systems (proposed by Liberopoulos and Dallery) are pull systems if $\mathrm{K}<\infty$ and are push systems otherwise.

- POLKA systems proposed by Suri is a pull system because, like kanban and CONWIP, WIP is limited by cards.
- PAC systems proposed by Buzacott and Shanthikumar are a pull system when the number of process tags (which serve to limit WIP) is less than infinity.

- MRP with a WIP constraint (as suggested by Axsäter and Rosling ) is a pull system

\section{Analysis of Factors Which Determine the Decision for Pull/Push Strategy}

Some of the important factors which help to determine whether the organization should opt for Pull strategy or Push Strategy are given below. There may be some more factors which might play a role in deciding whether to follow a push or pull strategy. But the factors given below are the major factors which cover most of the industries whether manufacturing or service related industry. Thus, the factors discussed can help any organization to decide whether they should go for push/pull strategy.

i Demand- Demand plays a vital if it's a dependent demand or demand known with certainty the industry should go for pull system, but if demand cannot be forecasted with certainty the push system is the solution. Wemmerlov, $U$ [8] studied the behavior of lot-sizing procedures in the presence of forecasting errors. Jump up J., Ashayeri; R.P., Kampstra [9] worked on Demand Driven Distribution: The Logistical Challenges and Opportunities. There is no perfect forecasting method which can predict the demand with certainty. Although using forecasting techniques and past data, we can plan the master production schedule, but it's impossible to predict the exact demand. Therefore, more the uncertainty in demand more chances of using push strategy to use the present capacity to the fullest. Although most of the studies done are not sure whether push or pull system would provide better service at lower cost in case of uncertain demand. The reduction in forecasting error can be the best solution.

ii Price of Goods- If the item is a very costly item than it would always be better for the organization to go for pull system. For example - High end cars. If the product is not very costly in that case company can think of push system, the best example of the same is salt.

iii Competition- If there is a bitter completion in that case, the company would be advised to go for push system. Here customer might not be willing to wait for long and might choose the competitor's product.

iv Product life cycle- In the case the product would become absurd after some time it is advisable to follow push strategy for example electronic 
gadgets. As the life cycle of these products have been shrunk

$\mathrm{v}$ Variety- If lot of variety is possible in the product. In that case also it would be better to have a pull system. For example -Automobile sector, where even one model might have different variants, so it is better for the manufacturer to follow pull strategy. The other example can be paint industry.

vi E-commerce- For E-Commerce companies for most of the products it can be pull system, but with the condition that their suppliers would be able to supply their products on time. For example Amazon.com would keep track of the products available with the supplier and would be shown to the customer at the offered price. If some of the item is not available for any reason it would be reflected in their system, they would remove that item immediately, once the customer places the order, the product is picked from the supplier and shipped to the customer. Thus, without keeping large inventories most of the products are available at Amazon.com

vii Brick and Mortar Department Store- As it has been observed that in these stores demand is mostly stock dependent demand and for them the push system is the best system. For example- Wall Mart Stores, here we cannot think of pull strategy it would always survive on push strategy. Therefore strategy of the Wall Mart of providing the regular products at the minimum possible price.

viii Perishable Products- These products have some fixed life; therefore it is always advisable to have a pull system. As the product considered would of no use later therefore it is better to produce only if demand is there. Otherwise, after some it would be a complete loss to the organization.

ix New Product or Technology- For product based on new technology, it is always advisable to have Pull Strategy. As the risk associated is high, it is very difficult to predict the demand in advance.

$\mathrm{x}$ Information System- Another factor which plays a vital role is an information system and the responsiveness of suppliers, which determines whether you should go for Push or Pull system. If the complete supply chain is connected by the same information system, the inventory levels can be reduced to the optimal and pull system will be the ideal system. It will remove the bullwhip effect. The bullwhip effect is defined as a phenomenon whereby each upstream player in the supply chain tends to carry more and more inventory due to lack of visibility of the actual customer at the fag end of the supply chain.

The factors considered above might not be affecting all the industry, but at least some factors might help them to arrive at a decision for choosing either push/pull strategy. In some cases the industry can use the weighted mean score to decide about the strategy. In many situations, it's impossible for organizations to follow either completely push/pull system in that case they prefer to use both together as Push-Pull Based System defined below. Iman Niromand [10] has explained advantages and pitfalls of Push and Pull Strategies in Distribution Networks

\section{Push-Pull Based Strategy}

A push-pull-based supply chain strategy is an amalgamation of push-and pull-based strategies. The downstream operations from the initial raw material supplier end to another player in the chain are pursued on push-based strategy; while the remaining part of the chain is operated on pull based strategy as shown in figure 1. For example the designing, planning, and procurement of components are done through the push-based strategy by utilizing the aggregate demand forecasts for the various models and variants of the product. However, the assembling of the product starts only when the actual customer demand comes in at the retailer's end of the chain.

The paint industry can be considered as the best example of push and pull boundary, they have gained substantially by having a push-pull based system. In last few decades in lieu of completing the whole process of mixing colors at the large plants. They have started providing facility to retailers who can mix the color as per the demand of the customer. In other word, the color mixing was shifted from push to pull strategy. This helped to reduce the retailers in reducing the inventory also coping ever changing demand. The result is win-win situation for both the customer and retailer as the customer is delighted to get all colors available, whereas retailers are saving on the inventory costs and no possibility of shortages which was the major issue few decades back. 


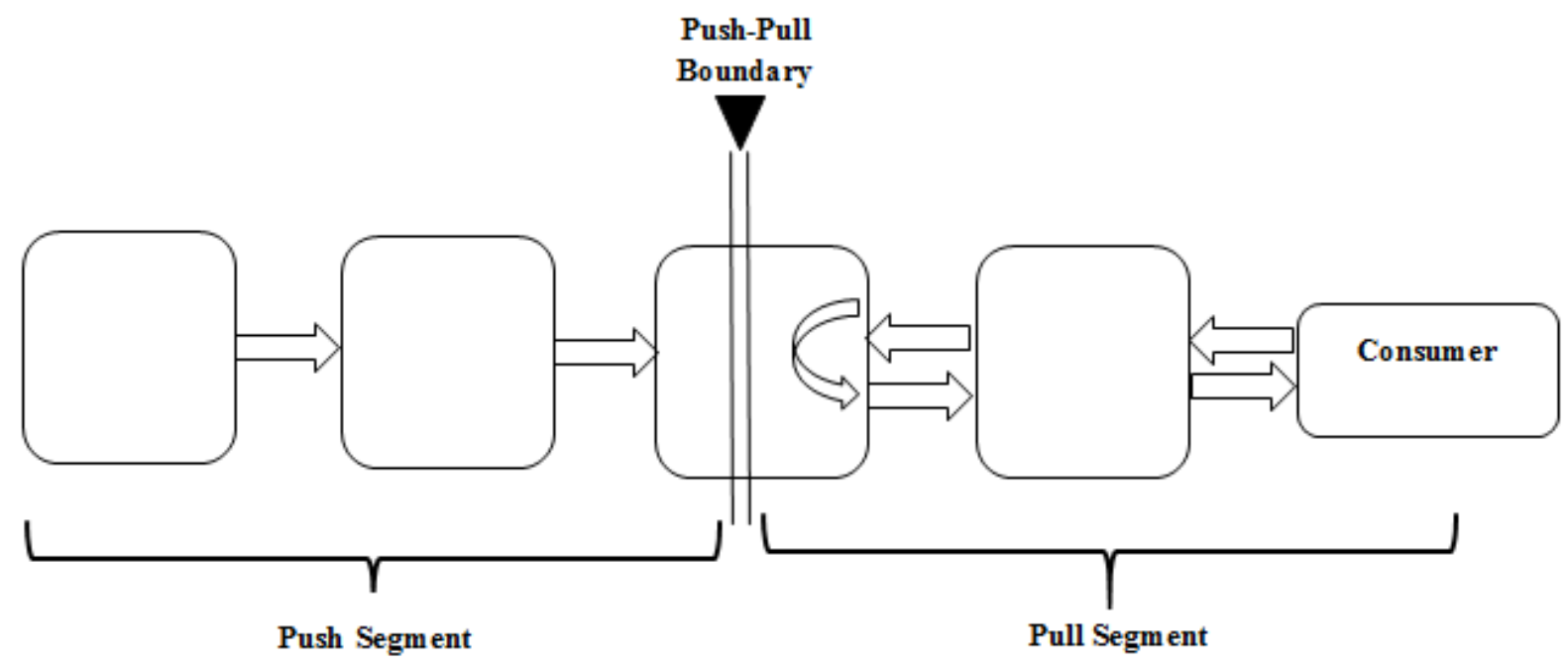

Figure 1. Source- www.cdn.ttgtmedia.com

A push/pull view of the supply chain categorizes processes based on whether they are initiated in response to a customer order (pull) or in anticipation of a customer order (push). This view is useful when to follow which strategy as can be seen in the figure 1, push/pull boundary, this boundary separates push processes from pull process. Thus, here organization is following combination of both push and pull strategy.

\section{Conclusions}

This study proves that all the processes in a supply chain fall into two categories either push/pull strategy depending on the timing of their execution in relation to the customer demand. Although in some cases they might use push-pull based system, it depends on the type of industry. This study provides the various factors which help the organization in deciding whether to go for a push/pull strategy. This paper also provides the classic examples of push and push strategy suggested by the various authors. Thus, this study can help retailers and wholesalers to decide whether they should opt for push/pull strategy or the mixed of both the strategies. Some examples are provided in the study where the organization initially having push system has moved from push to pull strategy with rapid advancement in technology. This study can be further extended to the industry specific study on use of push/pull strategy.

\section{REFERENCES}

[1] Sarkar B.R. and Fitsimmons J. A. (1989) the performance of push and pull system: a simulation and comparative study. International Journal of Production Research, 27(10),
1715-1731.

[2] Pyke, D.F and Cohen, M.A (1990), Push and Pull in manufacturing and distribution systems. Journal of Operations management. 9(1), 24-43.

[3] Terry P. Harrison, Hau L. Lee and John J. Neale (2003). The Practice of Supply Chain Management. Springer. ISBN 0-387-24099-3.

[4] Zhao, X and Lee T.S (1993). Freezing the master production schedule for material requirement planning system under demand uncertainty. Journal of Operations Management, 11(2), 185-205

[5] Kim Kilsun, Chhajed Dilip and Palekar S. Uddatta (2002). A comparative study of the performance of push and pull in the presence of emergency orders, International Journal of Production Research 7, 1627-1646.

[6] W. Masuchun, and J. W. Patterson (2004) Comparison of push and pull control strategies for supply network management in a make-to-stock environment. International Journal of Production Research. 42(20), 4401-4419.

[7] Jump up Hopp, Wallace J.; Spearman, Mark L. (2014). To pull or not to pull: what is the question? Manufacturing Service Operations Management. 6(2), 133-148.

[8] Wemmerlov, U (1989) The behavior of lot-sizing procedures in the presence of forecast errors. Journal of Operation Management, 8 (1), 37-42.

[9] Jump up J., Ashayeri; R.P., Kampstra (2005). Demand Driven Distribution: The Logistical Challenges and Opportunities. (Department of Econometrics and Operations Research Tilburg University). $\mathrm{http}: / /$ citeseerx.ist.psu.edu/viewdoc/download?doi=10.1.1.5 46.350\&rep=rep $1 \&$ type $=p d f$

[10] Iman Niromand (2016). Advantages and Pitfalls of Push and Pull Strategies in Distribution Networks. https://blog.kinaxis.com/2016/09/advantages-pitfalls-pushpull-strategies-distribution-networks/ 